\title{
Attenuation of Pressor Responses to Laryngoscopy and Endotracheal Inbtubation with Intravenous Esmolol Vis-⿳亠丷⿵冂-Vis Intravenous Lignocaine in Cardiac Diseases (A Comparative Study)
}

\author{
Bajracharya U**
}

\section{Summary}

The effect of i.v. esmolol and lignocaine in anaesthetized patients during laryngoscopy and intubation was studied in 90 patients with various cardiac diseases. Pulse rate, systolic and diastolic blood pressure and mean arterial pressure were measured to assess the cardiovascular response. It was concluded that Esmolol was significantly superior to Lignocaine in blunting the haemodynamic response to laryngoscopy and tracheal intubation.

Keywords: Cardiovascular response, laryngoscopy, intubation, attenuation, esmolol, lignocaine

\section{Introduction}

Laryngoscopy and endotracheal intubation, an integral part of anaesthetic procedures, is an invasive method of ventilating patient under anaesthesia. Significant cardiovascular changes as depicted by the rise in blood pressure (by $40 \%$ ) and heart rate (by $20 \%$ ) are well documented during this procedure, which causes mechanical stimulation to epipharynx, laryngopharynx and tracheobronchial tree causing increased reflex sympathetic activities (releasing catecholamines) $(3,4,5,7,11,20,21,29)$ The response is self limiting and well tolerated in healthy individuals. However, it may be hazardous to patients with hypertension, myocardial insufficiency and cerebrovascular diseases.(9) With varying effect, a number of pharmacological modalities (Opioids:Fentanil,_2- agonist: e.g. Clonidine, _- Blockers e.g. Propanolol) and techniques (Uses of Fibreoptic Laryngoscope \& Mc coy Laryngoscopic Blade) have been put into practice to ameliorate the cardiovascular effects of endotracheal intubation.

* Dr. Uday Bajracharya, MBBS, MD.

Maj., Consultant Anaesthesiologist

Shree Birendra Hospital, Chhauni

\section{Materials}

The present study consisted of a total population of 90 patients of either sexes scheduled for variou: corrective cardiac surgical procedures under genera anaesthesia. They were in ASA Grade II \& Grads III.Age groups of all patients were between 18-5: years. Patients were excluded from the study if the were less than 18 or more than 55 years old or it they had known allergy/hypersensitivity to Esmolo and Lignocaine or if they had COPD/ Asthma o AV Block.or hypotension /severe hypertension of bradycardia. Difficult intubation (Mouth opening $<2 \mathrm{~cm}$, thyromental distance $<3 \mathrm{~cm}$ ) cases were alse excluded. Any case requiring more than 10 seconds for intubation will be excluded as stimulus fol longer period may cause exaggerated presso: response. The study was conducted it cardiothoracic center, Pune.

\section{Methods}

This is a randomized controlled study. The patients were randomly allocated to three groups eact consisting of 30 patients. Group A (Controlgroup) did not receive Esmolol or Lignocaine.Group $B$ received Esmolol.Group $\mathrm{C}$ received Lignocaine. Al received Diazepam $0.1 \mathrm{mg} / \mathrm{kg}$ orally at $2200 \mathrm{hrs}$ th night prior to surgery and the same dose in thi morning of surgery at $0600 \mathrm{hrs}$.In the OT monitoring was applied before medication an included an electrocardiogragh for heart rate an ECG, and.pulse oximeter. Under L/A (2? lignocaine), radial artery was cannulated and th pressure tubing was attached to transducer an: hence to invasive blood pressure monitor.Followin: a 3 minute preoxygenation $(\mathrm{O} 2-6 \mathrm{ltr} / \mathrm{min}$ anesthesia was induced with thiopentone in sleepdose. (3-5 mg/kg titrated to effect). It was jus preceded by muscle relaxation with non depolarizing group viz.i.v. Vecuronium $100 \mu \mathrm{gm}$ 
$\mathrm{kg}$, followed by Esmolol $0.5 \mathrm{mg} / \mathrm{kg}$ i.v. (Gr. B. received $3 \mathrm{~min}$ before intubation.b) Lignocaine 2 $\mathrm{mg} / \mathrm{kg}$ i.v. (Gr.C. received $3 \mathrm{~min}$ before intubation). Laryngoscopy (Mcintosh) was performed followed by intubation after 3 minutes of administration of above drugs and after 3 minutes in Group $A$ without administration of above drugs. The tube was secured after confirming equal air entry bilaterally in the chest. The patients were not draped/cleaned or positioned for first 15 minutes after intubation to avoid stimuli. Maximum HR.\& Intra-arterial BP (SAP, DAP, \& MAP) were recorded before induction (X), at the time of induction (Y),during intubation ( $Z$ ), after intubation, for duration of 10 min. at an interval of 2 minutes $\left(Z_{2}, Z_{4}, Z_{6}, Z_{8}\right.$, $Z_{10}$, $)$ \& after 15 minutes $\left(Z_{15}\right)$. Anaesthesia was maintained by $\mathrm{O}_{2} \quad(33 \%), \mathrm{N}_{2} \mathrm{O}(66 \%)$ and Isoflurane $(0.5-1 \%)$. After recording the last reading (at 15 minute) injection, fentanyl $2 \mu \mathrm{gm} /$ $\mathrm{kg}$. I.V. was given; Fentanil is also a good drug to obtund the pressor response. No opioid was used in pre-medication Statistical Analysis was carried out through ANOVA as there were more than 2 groups which were compared by unpaired ' $t$ ' test and mean values were compared between groups $B \& C$.

\section{Observation And Results}

\begin{tabular}{|l|c|c|c|c|}
\hline Sex & Group A & Group B & Group C & Total \\
\hline Males & 15 & 15 & 15 & 45 \\
\hline Females & 15 & 15 & 15 & 45 \\
\hline Total & $\mathbf{3 0}$ & $\mathbf{3 0}$ & $\mathbf{3 0}$ & $\mathbf{9 0}$ \\
\hline
\end{tabular}

Table -I: Sex distribution

\begin{tabular}{|l|c|c|c|c|}
\hline Age & Group A & Group B & Group C & Total \\
\hline $\mathbf{1 8 - 2 0}$ & 5 & 5 & 5 & 15 \\
\hline $\mathbf{2 1 - 3 0}$ & 5 & 5 & 5 & 15 \\
\hline $\mathbf{3 1 - 4 0}$ & 5 & 5 & 3 & 13 \\
\hline $\mathbf{4 1 - 5 0}$ & 5 & 5 & 12 & 22 \\
\hline $\mathbf{5 1 - 5 5}$ & 10 & 10 & 5 & 25 \\
\hline Total & $\mathbf{3 0}$ & $\mathbf{3 0}$ & $\mathbf{3 0}$ & $\mathbf{9 0}$ \\
\hline
\end{tabular}

Table-II: Age distribution

\begin{tabular}{|l|c|c|c|c|}
\hline & Group A & Group B & Group C & Total \\
\hline CAD & 10 & 10 & 10 & 30 \\
\hline VHD & 10 & 10 & 10 & 30 \\
\hline CHD & 10 & 10 & 10 & 30 \\
\hline Total & 30 & 30 & 30 & 90 \\
\hline
\end{tabular}

Table-III: Disease distribution

\section{Legend:}

CAD (Coronary artery diseases) included double \& triple vessel diseases

VHD (Valvular heart diseases) included MS, MR, AS, \& AR

CHD (Congenital heart diseases) included ASD, $\&$ VSD.

\begin{tabular}{|l|c|c|c|c|}
\hline & CHD & VHD & IHD & Total \\
\hline $\mathbf{1 8 - 2 0}$ & 13 & 5 & - & 18 \\
\hline $\mathbf{2 0 - 3 0}$ & 10 & 10 & - & 20 \\
\hline $\mathbf{3 1 - 4 0}$ & 5 & 10 & - & 15 \\
\hline $\mathbf{4 1 - 5 0}$ & 2 & 5 & 10 & 17 \\
\hline $\mathbf{5 1 - 5 5}$ & - & - & 20 & 20 \\
\hline TOTAL & $\mathbf{3 0}$ & $\mathbf{3 0}$ & $\mathbf{3 0}$ & $\mathbf{9 0}$ \\
\hline
\end{tabular}

Table -IV: Disease V/S age profile

\begin{tabular}{|l|c|c|c|c|}
\hline ASA Status & Group A & Group B & Group C & Total \\
\hline II & 5 & 5 & 5 & 15 \\
\hline III & 25 & 25 & 25 & 75 \\
\hline TOTAL & 30 & 30 & 30 & 90 \\
\hline
\end{tabular}

Table -V: ASA physical status

\begin{tabular}{|l|c|c|c|c|}
\hline $\begin{array}{l}\text { Type of } \\
\text { surgery }\end{array}$ & Group A & Group B & Group C & Total \\
\hline AVR & 4 & 4 & 4 & 12 \\
\hline MVR & 5 & 5 & 5 & 15 \\
\hline DVR & 1 & 1 & 1 & 3 \\
\hline CABG & 10 & 10 & 10 & 30 \\
\hline VSD Correction & 5 & 5 & 5 & 15 \\
\hline ASD Correction & 5 & 5 & 5 & 15 \\
\hline Total & 30 & 30 & 30 & 90 \\
\hline
\end{tabular}

Table -VI Categorization of the surgery 
Legend:

AVR -- Aortic Valve Replacement

MVR - Mitral Valve Replacement

DVR - Double Valve Replacement

CABG - Coronary Artery By Pass Grafting

VSD - Ventricular Septal Defect

ASD- Atrial Septal Defect

\begin{tabular}{|l|r|r|r|r|r|r|r|r|r|}
\hline & $\mathbf{X}$ & $\mathbf{Y}$ & $\mathrm{Z}_{\mathbf{0}}$ & $\mathrm{Z}_{\mathbf{2}}$ & $\mathrm{Z}_{\mathbf{4}}$ & $\mathrm{Z}_{\mathbf{6}}$ & $\mathrm{Z}_{\mathbf{8}}$ & $\mathrm{Z}_{10}$ & $\mathrm{Z}_{15}$ \\
\hline GROUP A & 90 & 94 & 100 & 110 & 120 & 118 & 115 & 110 & 100 \\
& \pm 8.2 & \pm 10.4 & \pm 8.3 & \pm 7.3 & \pm 10.4 & \pm 11.6 & \pm 10.2 & \pm 8.4 & +5.2 \\
\hline GROUP B & 90 & 88 & 88 & 80 & 74 & 78 & 80 & 84 & 88 \\
& \pm 8.3 & \pm 5.1 & \pm 4.2 & \pm 3.4 & \pm 4.5 & \pm 5.6 & \pm 6.2 & \pm 7.2 & \pm 8.2 \\
\hline GROUP C & 92 & 94 & 90 & 88 & 94 & 90 & 90 & 90 & 90 \\
& \pm 7.1 & \pm 8.2 & \pm 6.7 & \pm 7.4 & \pm 8.3 & \pm 7.2 & \pm 8.2 & \pm 8.1 & \pm 9.1 \\
\hline
\end{tabular}

Table 1: Changes in heart rate at various intervals after laryngoscopy and endotracheal intubation values expressed as mean $+S D$

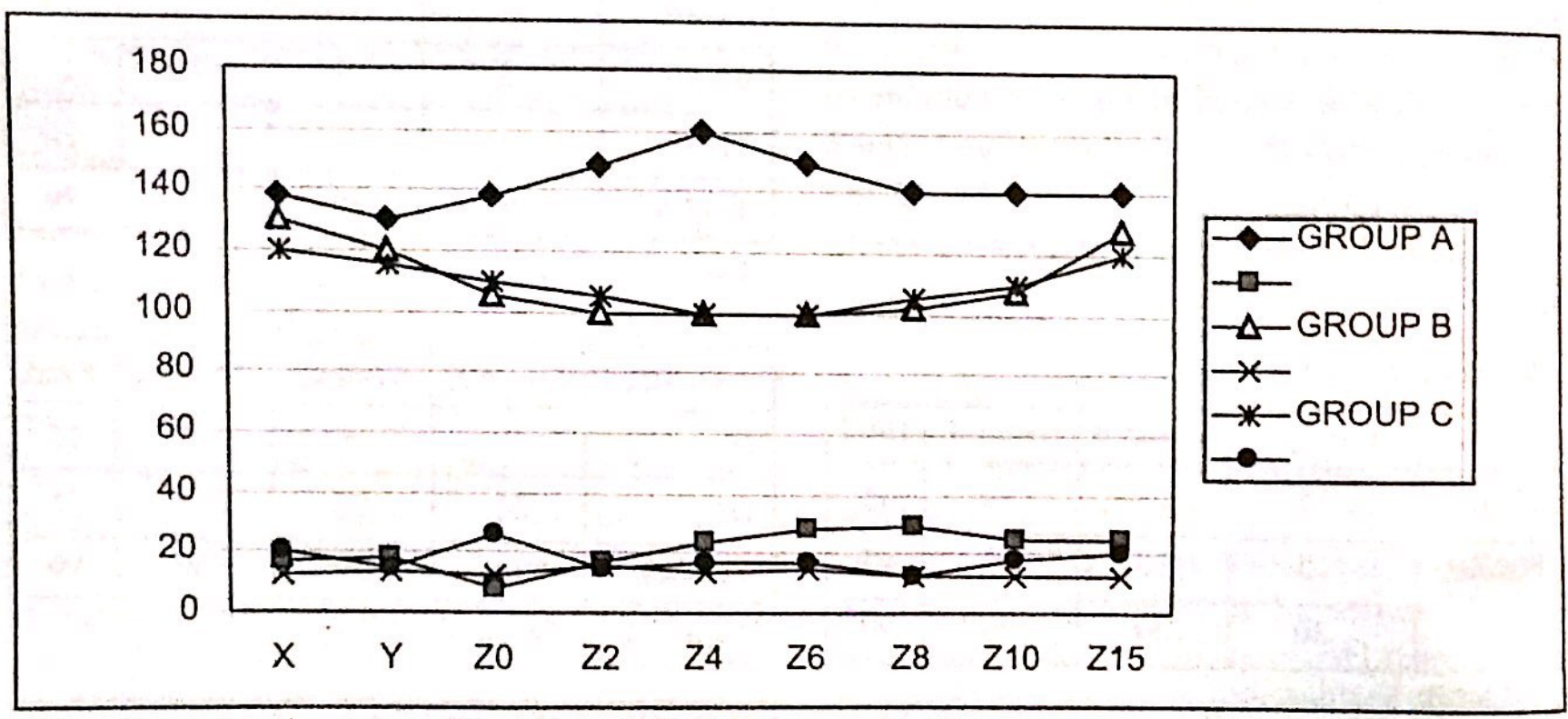

Line chart showing Mean Heart Rate (BPM) Change with Time

\begin{tabular}{|l|r|r|r|r|r|r|r|r|r|}
\hline & $\mathbf{X}$ & $\mathbf{Y}$ & $\mathbf{Z}_{\mathbf{0}}$ & $\mathbf{Z}_{\mathbf{2}}$ & $\mathrm{Z}_{4}$ & $\mathbf{Z}_{6}$ & $\mathbf{Z}_{\mathbf{8}}$ & $\mathbf{Z}_{10}$ & $\mathbf{Z}_{15}$ \\
\hline GROUPA & 138 & 130 & 138 & 148 & 160 & 150 & 140 & 140 & 140 \\
& \pm 17.2 & \pm 18.3 & \pm 8.3 & \pm 16.5 & \pm 24.3 & \pm 28.4 & \pm 29.9 & \pm 25.1 & \pm 25 \\
\hline GROUP B & 130 & 120 & 105 & 100 & 100 & 100 & 102 & 108 & 128 \\
& \pm 11.9 & \pm 13.3 & \pm 12.7 & \pm 16.1 & \pm 14.1 & \pm 14.5 & \pm 12.9 & \pm 12.5 & \pm 12 \\
\hline GROUP C & 120 & 115 & 110 & 105 & 100 & 100 & 105 & 110 & 120 \\
& \pm 20 & \pm 15.1 & \pm 26.2 & \pm 15 & \pm 17 & \pm 17 & \pm 13 & \pm 18.1 & \pm 20.1 \\
\hline
\end{tabular}

Table 2: Change in systolic arterial pressure at various intervals after laryngoscopy and intubation Values expressed as mean $+\mathrm{SD}$ 


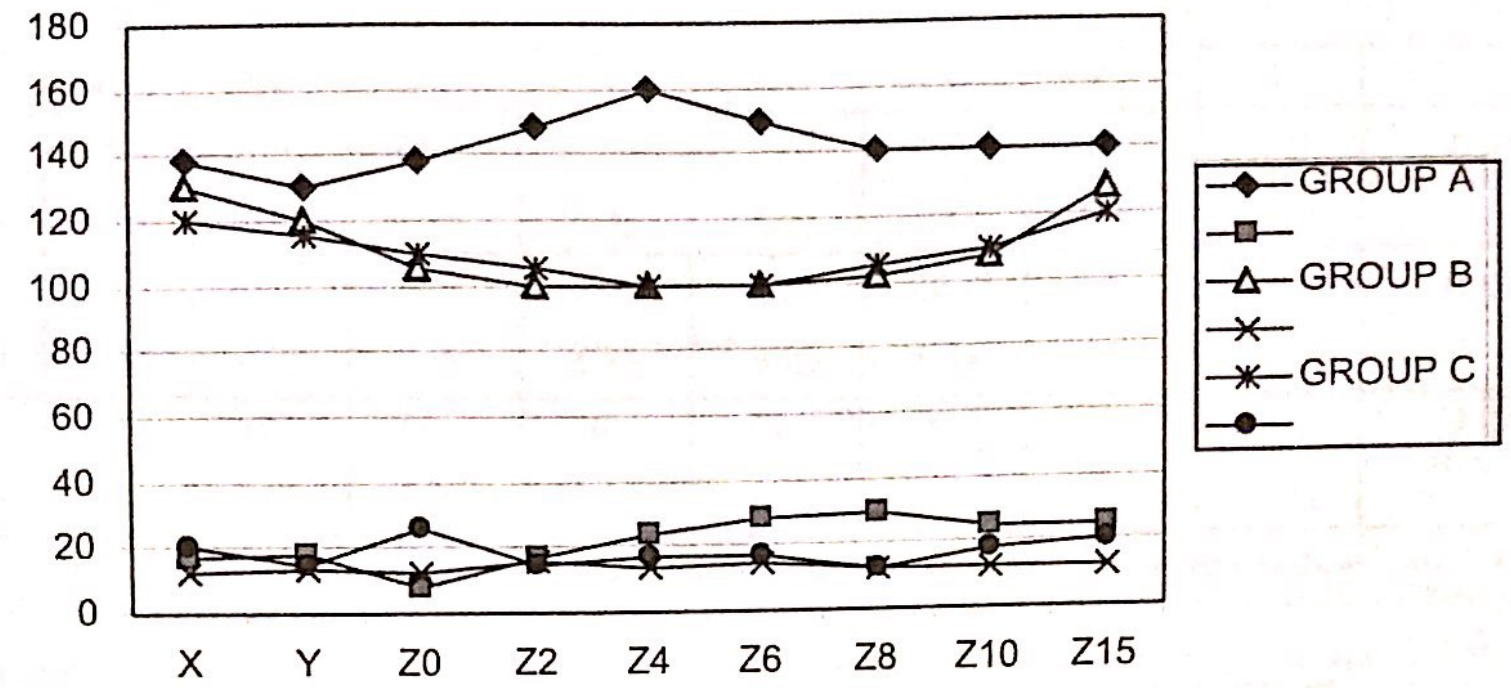

Line chart showing nean SAP ( $\mathrm{mmHg}$ ) change with time

\begin{tabular}{|l|r|r|r|r|r|r|r|r|r|}
\hline & $\mathbf{X}$ & $\mathbf{Y}$ & $\mathbf{Z}_{\mathbf{0}}$ & $\mathbf{Z}_{\mathbf{2}}$ & $\mathbf{Z}_{\mathbf{4}}$ & $\mathbf{Z}_{\mathbf{6}}$ & $\mathbf{Z}_{\mathbf{8}}$ & $\mathbf{Z}_{\mathbf{1 0}}$ & $\mathbf{Z}_{\mathbf{1 5}}$ \\
\hline GROUP A & 88 & 86 & 88 & 90 & 110 & 100 & 100 & 90 & 90 \\
& \pm 11.7 & \pm 13.1 & \pm 12.6 & \pm 15.7 & \pm 17.5 & \pm 18.3 & \pm 20.9 & \pm 19 & \pm 13.2 \\
\hline GROUP B & 90 & 80 & 80 & 70 & 80 & 84 & 86 & 88 & 90 \\
& \pm 7.9 & \pm 10 & \pm 8.1 & \pm 5.2 & \pm 7.1 & \pm 8.2 & \pm 7.3 & \pm 18.3 & \pm 7.8 \\
\hline GROUP C & 94 & 90 & 88 & 86 & 88 & 90 & 92 & 94 & 94 \\
& \pm 8.1 & \pm 7.4 & \pm 8.2 & \pm 6.4 & \pm 7.2 & \pm 7.3 & \pm 7.4 & \pm 8.1 & \pm 7.1 \\
\hline
\end{tabular}

Table 3: Change in diastolic arterial pressure at various intervals after laryngoscopy and intubation values expressed as mean + SD

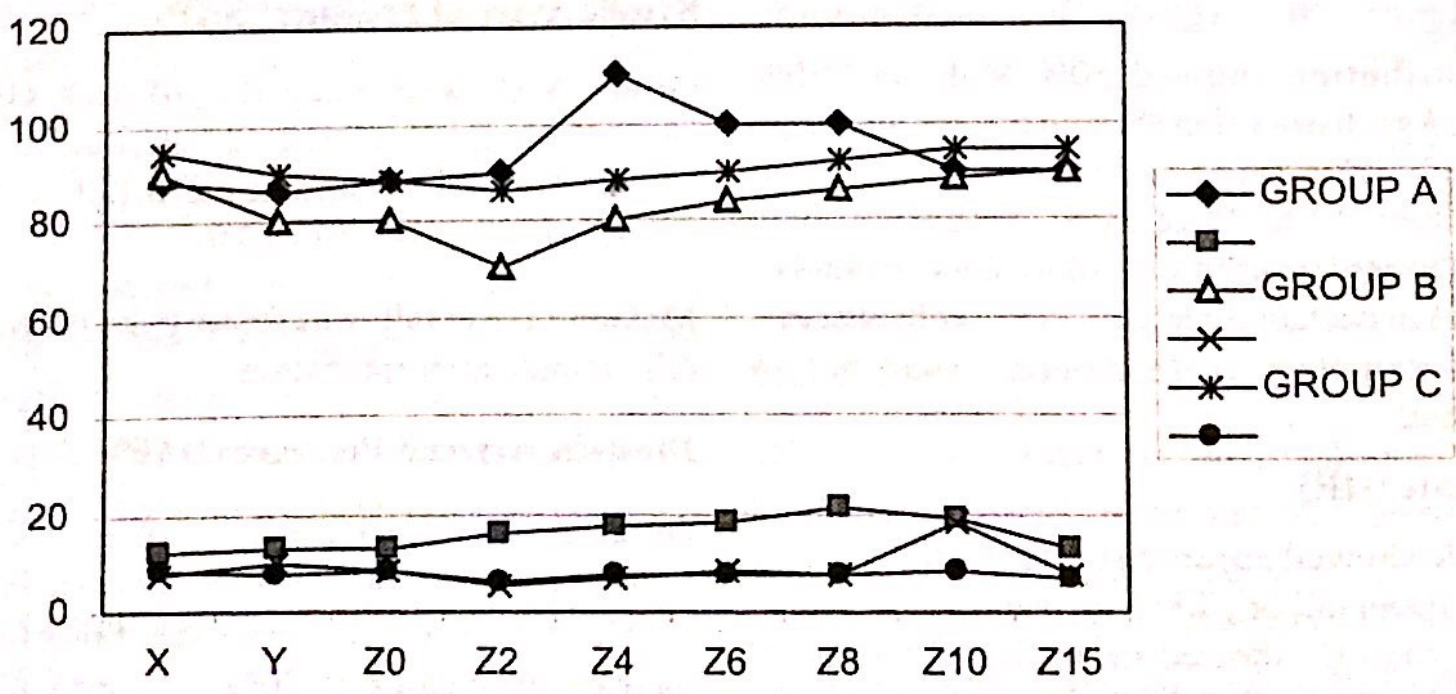

Line chart showing mean DAP ( $\mathrm{mmHg}$ ) change with time 


\begin{tabular}{|l|r|r|r|r|r|r|r|r|r}
\hline & $\mathbf{X}$ & $\mathbf{Y}$ & $\mathbf{Z}_{\mathbf{0}}$ & $\mathbf{Z}_{\mathbf{2}}$ & $\mathbf{Z}_{4}$ & $\mathbf{Z}_{\mathbf{6}}$ & $\mathbf{Z}_{8}$ & $\mathbf{Z}_{\mathbf{1 0}}$ & $\mathbf{Z}_{\mathbf{1 5}}$ \\
\hline Group A & 105 & 101 & 105 & 109 & 123 & 120 & 113 & 107 & 107 \\
& \pm 10.1 & \pm 8.9 & \pm 8.1 & \pm 8.5 & \pm 8.4 & \pm 9.5 & \pm 9.5 & \pm 9.6 & \pm 9.1 \\
\hline Group B & 103 & 93 & 93 & 83 & 87 & 89 & 94 & 99 & 103 \\
& \pm 9.4 & \pm 9.5 & \pm 8.5 & \pm 9.6 & \pm 9.8 & \pm 9.7 & \pm 8.5 & \pm 8.9 & \pm 9.6 \\
\hline Group C & 103 & 98 & 99 & 92 & 92 & 93 & 98 & 101 & 103 \\
& \pm 8.8 & \pm 8.9 & \pm 10.1 & \pm 10.3 & \pm 10.8 & \pm 9.5 & \pm 9.2 & \pm 8.5 & \pm 8.8 \\
\hline
\end{tabular}

Table 4: Change in Mean arterial pressure at various intervals after laryngoscopy and intubation values expressed as mean $+S[$

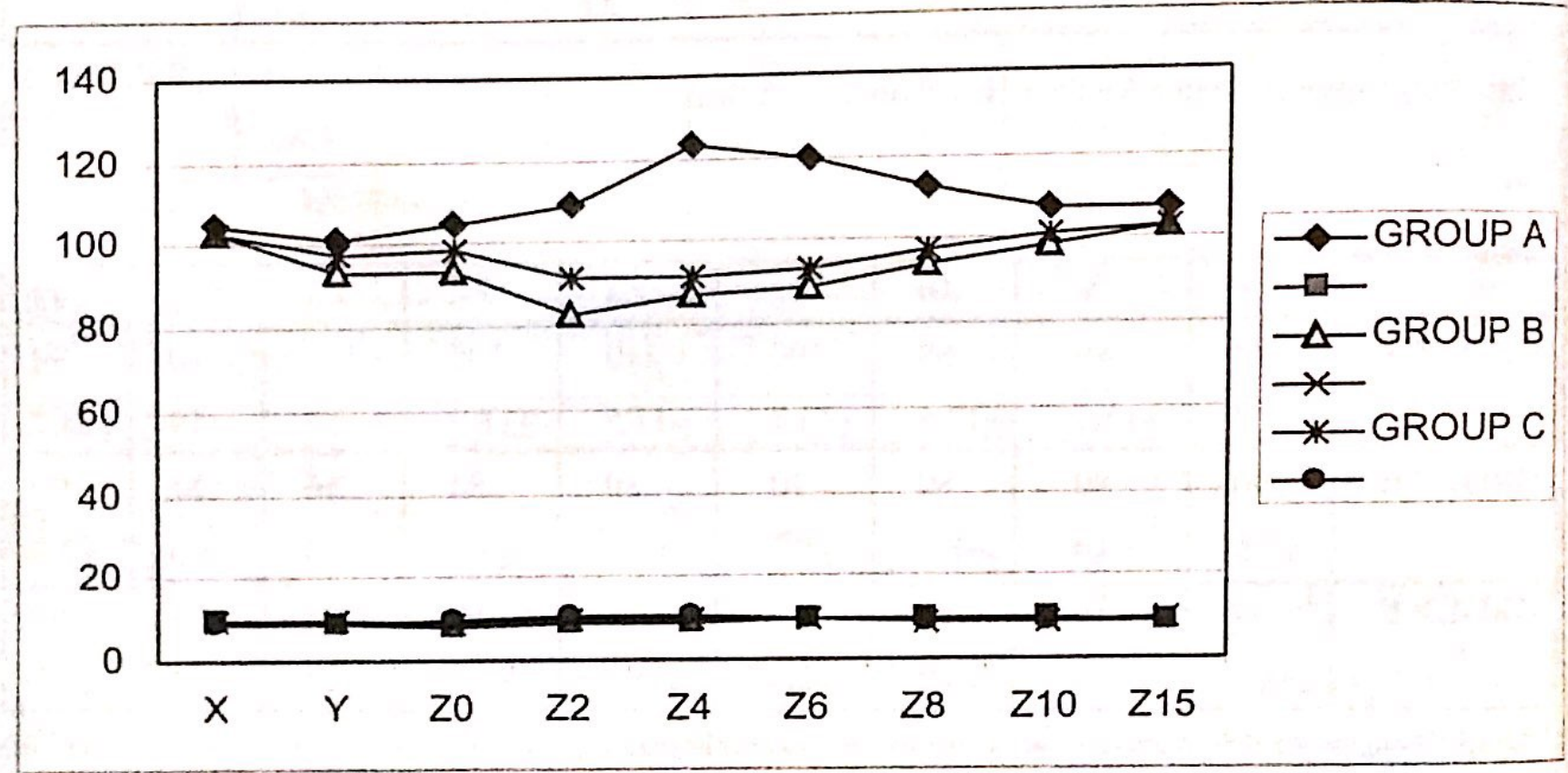

Line chart showing MAP ( $\mathrm{mmHg}$ ) change with time

\section{Results}

Sex distribution showed 50\% Male and 50\% Female. Age distribution showed that the age range between $51-55$ covered a maximum of $22.5 \%$ and that between 18 to $20 \& 21$ to 30 covered only $13.5 \%$. Disease distributions showed equal number $(33.33 \%)$ in each of three groups of cardic disease. These parameters of distribution were not so significant.

\section{Heart rate (HR)}

Group A showed mean rise of 33.\%.Group B showed mean fall of $17.7 \%$. \& increase in 5 cases @ $5 \%$.Group C showed mean rise of $0.02 \%$. \& increase in 10 cases@10\%

Maximum rise / fall was found to be between 2 \& 4 th minute after intubation.

\section{Sytolic Arterial Pressure (SAP)}

Group A showed mean rise of $16 \%$.Group B showed mean fall of $20 \%$. \& increase in 2 cases (a) $2 \%$ Group C - showed mean fall of $12 \%$. \& increase in 10 cases@15.3\%

Maximum rise/ fall was found to be between 2 \& 4th minute after intubation.

\section{Diastolic Arterial Pressure (DAP)}

Group A showed mean rise of $25 \%$. Group B showed mean fall of $22.9 \%$. \& increase in 2 cases (a) 5\% Group C showed mean fall of $6 \%$. \& increase in 10 cases@20\%

Maximum rise/ fall was found to be between $2 \&$ 4 th minute after intubation. 


\section{Mean Arterial Pressure (MAP)}

Group A showed mean rise of $17 \%$. Group B showed mean fall of $19 \%$, and increase in 2 cases (a) $4 \%$. Group C showed mean fall of $10 \%$, \& increase in 10 cases @ $12.7 \%$

Maximum rise/ fall was found to be between 2 \& 4th minute after intubation.

Esmolol was significantly superior to Lignocaine in blunting the haemodynamic response to laryngoscopy and tracheal intubation. $(\mathrm{P}<0.05)$

\section{Discussion}

Reid and Brace (1940) were the first to report the circulatory responses to laryngeal and tracheal stimulation in anaesthetized man.(19) These were tachycardia and a rise in aterial pressure. King et al (1951) found that during light general anaesthesia, when the epiglottis was elevated by a laryngoscope, there was an increase of systolic and diastolic pressure within 5 second. (12) Directly mediated reflexes, laryngovagal ( Airway spasm, apnea, bradycardia, arryhythmia or hypotension), laryngosympathetic (tachycardia, tachyarrhythmia or hypertension\} and laryngospinal \{Coughing, Vomiting or bucking / provide the final source of morbidity. Osamu. Yoshihirol, Masakatsu S., Hidenori T (1998) have shown that Skin Vasomotor Reflex (SVmR) predicts circulatory responses to laryngoscopy and intubation. The recent development of a laser Droppler flow-meter, which nonivasively measures skin surface local blood flow, is a useful tool to observe skin vasomotion. $S V m R$ is mediated by sympathetic nerves, because an -1 antagonist significantly reduces the amplitude of the $S V m R$, and a burst of skin sympathetic nerve activity preceeds the decrease in flow.(17) The minimal alveolar concentration (MAC-BAR) for endotracheal intubation is about $30 \%$ higher than MAC for surgical incision requiring a relatively deep level of anaesthesia to be established.

Korenga et al (1985), Donald et al (1990), Shane et al (1990), Miller et al (1991), Helfman et al (1991),
Chung et al (1992) Purdy et al (1992), Korpinen et al (1995), H Singh et al (1995), Kindler et al (1996), \& S Duttil et al (1999), also found that Esmolol was a better drug. $(8,10,22,23,25$, $)$ C.D. Miller and S.J. Warren (1990) showed lignocaine $1.5 \mathrm{mg} \mathrm{kg-}$ 1 given I.V. within 3 min of laryngoscopy failed to attenuate the cardiovascular responses to laryngoscopy and intubation. (24) Therefore lignocaine $2 \mathrm{mg} / \mathrm{kg}$ was given 3 minutes prior to intubation in this study.

V. Mehta, C.P. Bhasin and R.Sood, (1998) showed that peak rise in Esmolol group was $7.1 \%$ in $\mathrm{HR}$, $2.7 \%$ in SBP $3.8 \%$ in MAP $4.3 \%$ in DBP from base value compared to $13.0 \%$ in $\mathrm{HR}, 11.9 \%$ in SBP, $14.6 \%$ in MAP, $15.6 \%$ in DBP in lignocaine group. (28) They used Esmolol $100 \mathrm{mg}$ and lignocaine $1.5 \mathrm{mg} / \mathrm{kg} 2$ minute before intubation. It is highly comparable with our study.

\section{Conclusion}

The anesthetic sequence is full of stress to the patients. There is a demonstrable tachycardia and hypertension following laryngoscopy and intubation. Normal schedule of premedication and anaesthesia is not able to suppress this stress response, which lasts for approximately 10 minutes or even longer. The response can be ameliorated by using a beta blocker (Esmolol) and Class $1 \mathrm{~b}$ antiarrythmic drug (Lignocaine), and better by a combination of drugs or techniques. $(18,16,15,14,10,8,6)$

Esmolol is an ultrashort acting drug which by its brief action and cardioselectivity is near ideally suited to blunt the haemodynamic intubation response in comparison to widely used Lignocaine. $(27,25,23,22$,

IV Esmolol administered 3 minutes before intubation prevents the unwanted haemodynamic response in patients with VHD, CHD, IHD, thereby avoiding the serious life threatening complications like ventricular tachycardia, acute left ventricular failure, myocardial ischaemia and cardiovascular accident. 


\section{Reference}

1. Abou Madi M., Keszler H. and Yacoub J. M. Cardiovascular reactions to laryngoscopy and tracheal intubation following small and large intravenous doses of lidocaine. Canad. Anaesth. Soc.J.24:12, 1977.

2. C.D. Miller and S.J.Warre I.V. Lignocaine Fails to attenuate the Cardiovascular Response to laryngoscopy and tracheal intubation. British Journal of Anaesthesia 1990;65;216-219

3. C Prys - Roberts, R. Meloche and P.Foex, A. Ryder Studies of Anaesthesia in relation to hypertension: Cardiovascular Responses of treated and untreated patients. B.J. Anaesth, (1971), 43, 122.

4. C Prys - Robents J.M. Low, J.T. Harvey, and J. Dagnino Studies of Anaesthesia in relation to hypertension. VII: Adrenergic Responses to Laryngoscopy B. J.Anaesth ( 1986) 58, 471477

5. CPrys-Roberts, L.T. Greene, R. Meloche and PFoex Studies of Anaesthesia in relation to hypertension II: Hacmodynamic Consequences in induction \& endotracheal intubation. B.J. Anaesth (1971) 43, 531

6. Cuechaira, R.F. Benefier, D.J. Matteo, R.J. De Wood, M C Albin, M.S. (1986) Evaluation of Esmolol in controlling increases in heart rate \& B.P. during endotracheal intubation in patients undergoing carotid endarterectomy. Anacsthesiology $65,528-31$

7. Derbyshire D.R. Chmielewski A., Fell D., Vater M., Achola K. and Smith G (1983),; Plasma catecholamine responses to To tracheal intubation. Brit. J. Anaesth, 55, 855

8. Donald R. Miller Md, Raymond J. Martineau MD, J.E. Wynands MD, Jeremy Hill MSc. Bolus administration of Esmolol for controlling the Haemodynamic response to tracheal intubation: the Canadian multicentre trial. Can J. Anaesth 1991/38:7 / pp 849-58

9. Fox E.J; Sklar G.D.; Hill C. H. Villanueva R and Kind B.D. (1997): Complications related to the pressor response to endotracheal intubation. Anaesthesiology 47, 524
10. Helfman SM, Gold MJ, DeLisser EA Herrington CA. Which drug prevent tachycardia and hypertension associated witk tracheal intubation: Lidocaine, fentanyl esmolol ? Anaesthesia and Analgesia 199! Apr; 72(4); 482-6

11. Helfman SM, Herrington CA and Gold M] Esmolol \& Circulatory changes " laryngoscopy and intubation. Anesth Ana $1991 ; 72$ (5) 594-5.

12. King B. D; Harris L.C. Greifenstein F.E. an Elder J.D. and Gripps R.D. ( 1951): Refle: circulatory responses to direct laryngoscop: and endotracheal intubation. Anaesthesiology 12,556 .

13. K.J. Achola, M.J. Jones, R.W.D Mitchell an G. Smith Effects of beta- adrenocepto antagonism on the cardiovascular an: catecholamine responses to tracheal intubation Anaesthesia, 1988, Volume 43, Pages 433-436

14. Kindler CH. Schumacher PG, Schneider MC Urwyler A. Effects of intravenous lidocain: and / or esmolol on haemodynamic response to laryngoscopy and intubation: a double blind controlled clinical trial. Journal of Clinica Anaesthesia 1996; Sept; 8 (6); $491-6$

15. Korenga GM, Kirkpatrick A, Lord JG Barbaras E et al.Effects of esmolol or tachycardia induced by endotrachea intubation. Anesth Analgesia 1985; 64:185 304

16. Mitra S., Sharma S., Grover V.K. et al: Esmolo blunts the haeodymamic response to trachea intubation in treated hypertensive patients Canadian J. of Anaesthesia 43, 778, 1996

17. Osamu Shimoda, MD., Yashihiro Ikuta, MD Masakatsu Sakamoto, MD, Hidenori terasak MD. Skin vasomotor Reflex Predict Circulatory Responses to Laiyngoscopy an Intubation. Anaesthesiology V 88, No.2 Fe 1998

18. Pai A, Sharma KS, Kulkarni AP, Upadhya SM. Esmolol for attenuating 0 sympathoadrenal response durin laryngoscopy and intubation. B.J. Anaest Clin Pharmacol 1998; 14- 55-8 
19. Reid L.C. and Brace D.E. (1940): Intubation of the respiratory tract and its reflex effect upon the heart; Surg Gynaecol and Obst, 70, 157162

20. Russell W.J. Morris R.G., Frewin D.B. and Drew S.E. (1981). Changes in plasma catecholamine concentrations during endotracheal intubation. B.J. Anaesth, 53, 837

21. Stoelting R.K.; Blood Pressure and heart rate changes during short duration laryngoscopy for tracheal intubation. Anaesth.Analg. 57:197 199, 1978

22. Shane Sheppard MD FRPC, Chris J. Wagle, MD FRCPC Leo Strunin MD FRCPC; A bolus dose of Esmolol attenuates tachycardia and hypertension after tracheal intubation. Can J. Anaesth 1990 37:2/ pp 202-5.

23. Sheppard S, Eagle CJ, Strunin L.A bolus dose of esmolol attenuates tachycardia and hypertension after tracheal intubation.Can J. Anaesth 1990: 37;37; 202-5.

24. Splinter WM: (1990) Lidocaine does not attenuate the haemodynamic response of children to laryngoscopy. Anaesth.Analg 70: 385
25. Singh H, Vichetvejpaisal P, Gaines GY, White $\mathrm{PF}$, Camparative effects of lidocaine, esmolol and nitroglycerin in modifying the haemodynamic response to laryngoscopy and intubation Journal of Clinical Anaesthesia 1995; Feb; 7(1);5-8

26. Takeshima K. Noda K, Higaki $M$; Cardiovascular response to rapid anaesthetic induction and endotracheal intubation, Anaesth Analg. Current Researches 1967; 43; 201

27. Vacevic M. Purdy GM, Ellis Fr. Esmolol hydrochloride for management of the cardiovascular stress response to laryngoscopy and tracheal intubation. British Journal of Anaesthesia 1992;62; 529-30.

28. Vivek Mehta, C.P. Bhasin, R.Sood Comparison of Esmolol and Lignocaine for attenuation of stress response to laryngoscopy and intubation. XLV Annual National Conference, ISA, CME, 97 -FP 101.

29. Wyeoff C.C. (1960) Endrotracheal intubation: Effects on blood pressure and pulse rate. Anesthesiology, 21, 153-158 